\title{
Influence of positioning of $\mathrm{L} 4-5$ disc prostheses on functional outcomes and sagittal balance: 2-year follow-up of a cohort of 38 patients
}

\author{
Jean Meyblum, MD, ${ }^{1}$ Baptiste Boukebous, MD, ${ }^{2}$ Pierre Diviné, MD, ${ }^{1}$ Philippe Cottin, MD, \\ Charles-Henri Flouzat Lachaniette, MD, PhD, ${ }^{3}$ and Thierry Bégué, MD, PhD ${ }^{1}$ \\ 1Department of Orthopaedic and Traumatological Surgery, University of Paris-Sud; '2Department of Orthopaedic and \\ Traumatological Surgery, University of Paris-Nord Val de Seine; and 'Department of Orthopaedic and Traumatological Surgery, \\ University of Paris-Est Créteil, Paris, France
}

OBJECTIVE The main objective of this study was to evaluate the influence of L4-5 total disc replacement (TDR) positioning on functional outcome at the 2-year follow-up. The secondary objective was to assess its influence on sagittal balance.

METHODS Prospective data were compiled for 38 single-level L4-5 ProDisc-O TDRs. Anteroposterior placement (APP) was the distance between the center of the implant and the center of the $L 5$ endplate divided by the total length of the L5 endplate. This ratio was expressed as a percentage (APP $0 \%-49 \%$, anterior off-centering; $50 \%$, perfect centering; and 51\%-100\%, posterior off-centering). The patients were divided into 3 groups depending on the APP and using quartile values: group 1, anterior placement (APP 0\%-46\%); group 2, central placement (APP 46.1\%-52\%, the 2 central quartiles); and group 3, posterior placement (APP 52.1\%-100\%). The sagittal balance parameters assessed were overall lordosis, segmental lordosis, and pelvic incidence. Adequate lordosis was defined for each patient according to their pelvic incidence. The Oswestry Disability Index and visual analog scale (VAS) scores for back and leg pain were assessed.

RESULTS The average APP was 48\% (range 40\%-64\%). There were 10 patients in group 1, 18 in group 2, and 10 in group 3. There was a significant difference in functional outcomes among the 3 groups. APP influenced the VAS back $(p=0.04)$ and VAS leg $(p=0.05)$ scores. Group 1 consistently showed the highest performance scores. No significant association between APP and the sagittal balance parameters was found. Patients who had preoperative sagittal imbalance or those who significantly modified their balance after the surgery had the poorest outcomes.

CONCLUSIONS Disc prostheses at L4-5 seem to provide better functional outcome when they are positioned anteriorly to the center of the vertebral body.

https://thejns.org/doi/abs/10.3171/2019.12.SPINE191117

KEYWORDS total disc replacement; anteroposterior placement; sagittal balance; Oswestry Disability Index; visual analog scale; lumbar

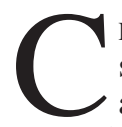

HRONIC low-back pain is a major public health issue. It is the main cause of disability before the age of 45 years, and it generates a direct medical cost of $€ 1.4$ billion each year in France.? Total disc replacement (TDR) has been proposed as a substitute for spinal fusion with good long-term functional outcomes in select patients. ${ }^{12,17,26}$ Several authors have investigated the variations in functional outcome depending on various parameters, such as surgical approach and morphological characteristics of the implant ${ }^{11,23}$ or operated level, ${ }^{27}$ but few have investigated the specific role of implant positioning on functional outcome and sagittal balance..$^{10,20}$ These studies have reported that off-centered Charité TDR devices (DePuy Spine) were more likely to result in poorer functional outcome, but the authors failed to specify the anterior or posterior nature of the off-centering.

Implant positioning has biomechanical consequences that might impact the functional outcome. For instance,

ABBREVIATIONS APP = anteroposterior placement; LL = lumbar lordosis; ODI = Oswestry Disability Index; PI = pelvic incidence; TDR = total disc replacement; VAS = visual analog scale.

SUBMITTED September 16, 2019. ACCEPTED December 5, 2019.

INCLUDE WHEN CITING Published online February 21, 2020; DOI: 10.3171/2019.12.SPINE191117. 
manufacturers recommend positioning TDR devices posteriorly, even though the compressive strength of the vertebral body is greater in the anterior portion. ${ }^{23}$ TDR positioning and restoration of disc height also impact facet joint kinematics and constraint and may lead to joint widening and subluxation. . $^{18,23,25}$ TDR placement also has an impact on segmental lordosis.

TDR placement is difficult, especially at L4-5 due to the bifurcation of the great vessels. The main objective of this study was to evaluate the influence of L4-5 TDR positioning on functional outcome at the 2-year follow-up. The secondary objective was to assess the influence of TDR positioning on sagittal balance.

\section{Methods \\ Patient Selection}

Prospective data were compiled for single-level L4-5 TDR from 2009 to 2015. Patients with chronic discogenic low-back pain for more than 6 months, with or without radicular symptoms, resulting from degenerative disc disease at L4-5 were included. All patients had received maximum medical treatment before surgery, including at least one epidural infiltration, according to the recommendations of the French High Authority of Health. We systematically looked for intervertebral instability, against which the prosthesis was indicated, on radiographs of the lumbar spine in flexion and extension. Preoperative scanning was systematically performed to check for the absence of degeneration of the posterior facet joints. In case of a risk factor for osteoporosis or doubt about poor bone quality, bone densitometry was performed. Only patients with complete 2-year follow-up data were included for analysis. All patients who had undergone vertebral surgery prior to the L4-5 TDR were excluded.

All patients had a preoperative visit and were followed postoperatively (Fig. 1) at day 45 (D45), 3 months (D90), 6 months (D180), 1 year (D365), and 2 years (D730). D730 was the date of late follow-up. According to French law, at the time of data collection, the opinion of an ethics committee was not required.

\section{Implant}

The ProDisc-O (DePuy Synthes) is a semiconstrained device. The device allows physiological motion in flexion, extension, axial rotation, and lateral bending similar to that observed in a normal spine. Modular keels are placed on implant endplates for implant-to-bone fixation.

\section{Surgical Technique}

The patient was positioned supine on a radiolucent operating table with his/her legs and arms abducted, and the surgeon worked between the patient's legs. The spine surgeon performed a left retroperitoneal approach through a midline incision. After safely retracting the great vessels, a complete single-level anterior discectomy was performed. Interbody space distractors were used to restore disc height as much as possible. Endplate preparation was performed using standard and ring curettes. The implants were impacted into the disc space, with a $45^{\circ}$ obliquity, under fluoroscopic guidance. All prostheses had a $10-\mathrm{mm}$
41 patients with isolated painful and pathological L4L5 disc. Medical treatment failure.

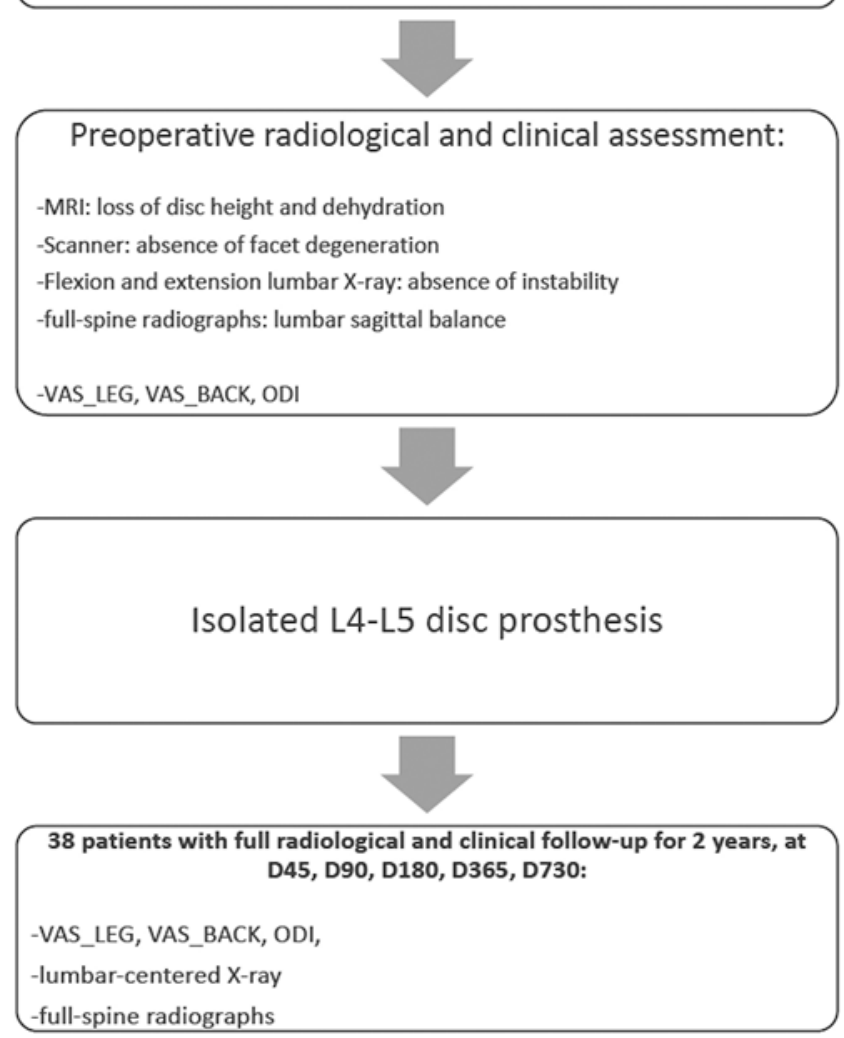

FIG. 1. Flowchart from patient inclusion to 2 years of radiological and clinical follow-up. $\mathrm{D}=$ day.

endplate with a $6^{\circ}$ lordosis angle. The variable among the implants was their anteroposterior size.

Postoperative care was standardized. Patients could get up the same day as the procedure. There was no immobilization or position limitation. Patients received preventive anticoagulation for 30 days after the procedure. Venous Doppler ultrasonography of the lower limbs was systematically performed on the 3rd day, in accordance with the practice of our department. Patients were on a residue-free diet until bowel function resumed. The analgesic treatment included paracetamol, tramadol, and a systematic laxative. Morphine was prescribed on request.

\section{Analysis of Implant Placement}

Implant placement was analyzed prospectively by a blinded independent single reviewer on nonrotated radiographs. Anteroposterior placement (APP) was determined on nonrotated standing lateral views by estimating the distance between the center of the implant and the center of the L5 endplate divided by the total length of the L5 endplate. This ratio was expressed as a percentage, with $0 \%$ to $49 \%$ being anterior off-centering (Fig. 2A), $50 \%$ being perfect centering (Fig. $2 \mathrm{~B}$ ), and $51 \%$ to $100 \%$ being 

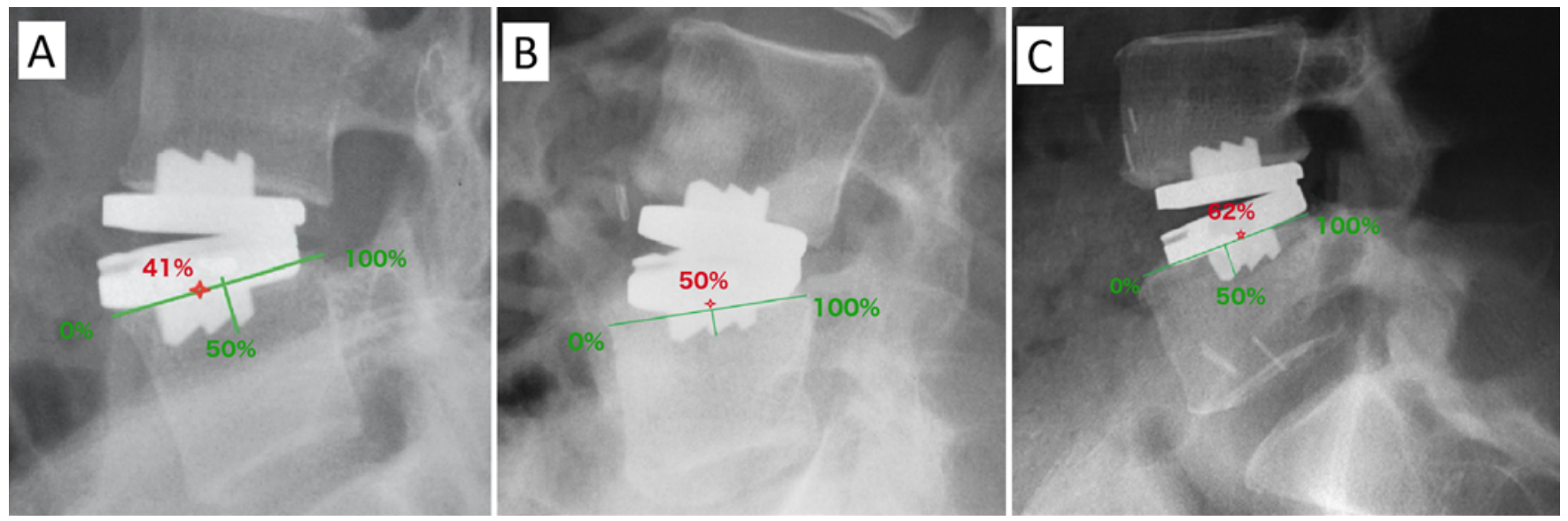

FIG. 2. A: Anterior TDR placement: APP $=41 \%(<50 \%)$. B: Perfect anteroposterior TDR placement: APP = 50\%. C: Posterior TDR placement: APP $=62 \%(>50 \%)$. Figure is available in color online only.

posterior off-centering (Fig. 2C). Coronal placement was evaluated in the same way: $50 \%$ meant perfect frontal centering; $0 \%-49 \%$, left off-centering; and $51 \%-100 \%$, right off-centering.

\section{Sagittal Balance Analysis}

Overall lumbar lordosis (LL) at L1-S1 and segmental lordosis at L4-5 were measured preoperatively and at late follow-up on full-spine lateral radiographs. We calculated the gain in LL (LLGain) and segmental lordosis (LLsegGain) preoperatively and at late follow-up using the following formulas: $\mathrm{LLGain}=$ (postoperative LL - preoperative LL)/preoperative LL; and LLsegGain = $($ postoperative segmental lordosis - preoperative segmental lordosis)/preoperative segmental lordosis.

Results are expressed as percentages. Pelvic incidence (PI) was measured to assess the adequacy of the LL with the morphological characteristics of the patients. Two types of PI-LL mismatch could be described: hyperlordosis was defined as a PI-LL mismatch $>-10^{\circ}$ and hypolordosis when the PI-LL mismatch was $<10^{\circ}$. Restored sagittal lumbar balance was defined in patients with preoperative lumbar hyperlordosis or hypolordosis who had adequate lordosis postoperatively.

\section{Clinical Evaluation}

Patients were assessed before surgery and at late follow-up. Clinical outcomes were analyzed globally and for both centered and off-centered TDRs. Patients were asked to complete the standardized Oswestry Disability Index (ODI) questionnaires ${ }^{4}$ and to rate their back and leg pain before surgery and at the late follow-up according to the visual analog scale (VAS). Clinical success was defined as $\mathrm{a} \geq 25 \%$ improvement in ODI. ${ }^{8}$

\section{Group Definition}

The patients were divided into 3 groups depending on the APP using quartiles. Group 1, anterior placement, was defined as an APP between $0 \%$ and $46 \%$ (first quartile). Group 2, central placement, was defined as an APP be- tween $46.1 \%$ and $52 \%$ (2 central quartiles). Group 3, posterior placement, was defined as an APP between $52.1 \%$ and $100 \%$ (fourth quartile).

\section{Statistical Analysis}

The data management and analysis were carried out using $\mathrm{R}$ software version 3.4.3. At first, the correlation between APP, coronal placement gain in segmental lordosis, and gain in LL was studied. Simple linear regressions were used. Then, the variations of ODI, VAS leg, and VAS back scores were studied among the 3 groups.

\section{Results}

\section{Patient Population}

Forty-one patients met the inclusion criteria during the study period, but 3 did not have complete clinical and radiological follow-up for 2 years. There were 17 males (44.7\%) and 21 females (55.3\%). The mean age at the time of surgery was 44 years (range $28-60$ years). Nine patients smoked before the procedure, but we found no influence of tobacco on the results. No patients had poor bone quality at the time of the procedure. One patient had an eventration without signs of severity and required no further surgery.

\section{Implant Placement and LL}

The average APP was 48\% (range 40\%-64\%, median $48 \%$ ). There were 10 patients in group 1, 18 in group 2, and 10 in group 3 . Regarding coronal placement, 5 of $38(13.2 \%)$ prostheses were perfectly centered, 21 of 38 (55.3\%) were lateralized on the left, and 12 of 38 (31.6\%) were lateralized on the right. There was a significant correlation between gain in segmental lordosis and APP ( $p$ $=0.02$ ) and a significant correlation between gain in segmental lordosis and gain in LL $(p=0.03)$ (Fig. 3). There was no significant direct correlation between APP and gain in LL. There was no significant correlation between coronal placement and LL or segmental LL. A positive gain in segmental and total lordosis was seen when the TDR devices were placed anteriorly (group 1). This gain 


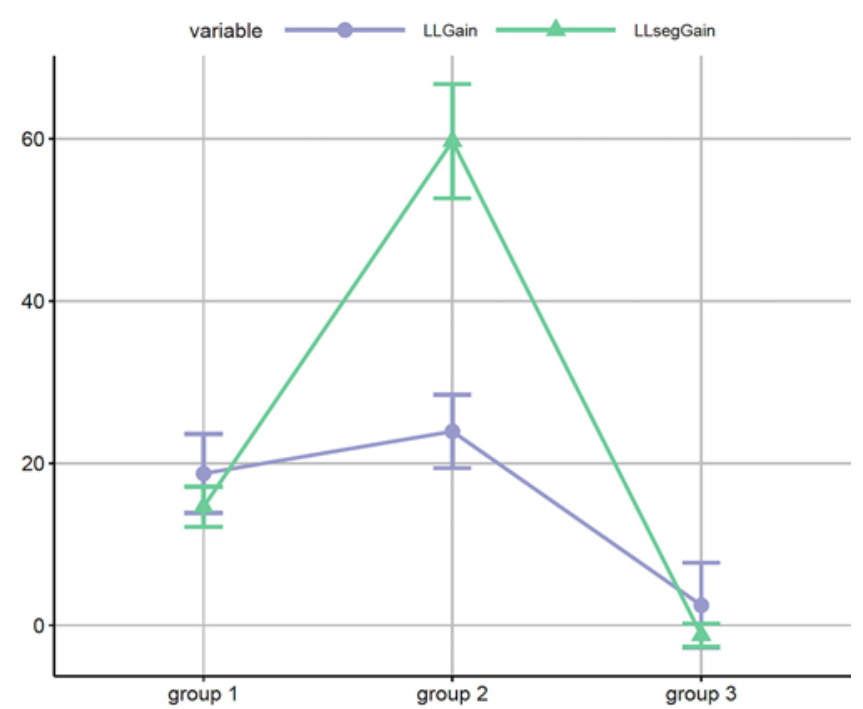

FIG. 3. Representation of the APP, the gain in LL (LLGain), and the gain in segmental lordosis (LLsegGain) correlations. Values on the $y$-axis are percentages. Group 1 represents the patients with prostheses placed the most anteriorly $(n=10)$, group 2 represents the patients with centered prostheses $(n=18)$, and group 3 represents the patients with the prostheses placed the most posteriorly $(n=10)$. There was a positive gain in segmental and total lordosis when the prostheses were placed anteriorly (groups 1 and 2). This gain was maximum when prostheses were placed close to the center (group 2). When placed beyond the endplate center, the gain in segmental lordosis suddenly decreases and can even be negative (group 3). Dots represent the means and error bars the $95 \% \mathrm{Cl}$. Figure is available in color online only.

was greatest when the TDR devices were placed close to the center (group 2). When placed beyond the endplate center, the gain in segmental lordosis suddenly decreases and can even be negative (group 3). The gain in LL curve follows the gain in segmental lordosis curve.

\section{Clinical Outcomes}

The mean preoperative VAS score for back pain was 7.1 (95\% CI 6.6-7.7), and at late follow-up it was $1.7(95 \%$ CI 1.1-2.4, $\mathrm{p}<10^{-5}$ ). The mean preoperative VAS score for leg pain was 6.8 (95\% CI 5.9-7.6), and at late follow-up it was $1.8\left(95 \% \mathrm{CI} 1.1-2.6, \mathrm{p}<10^{-5}\right)$. The mean preoperative ODI score was 60 (95\% CI 56-66), and at late followup it was $28\left(95 \%\right.$ CI $\left.21-34, \mathrm{p}<10^{-5}\right)$. Clinical success was achieved in 31 of $38(81.6 \%)$ patients at late follow-up. We could not distinguish two different groups of patients with different VAS leg and back profiles.

There was a significant difference in functional outcomes among the 3 groups. APP influenced the VAS back $(\mathrm{p}=0.04)$ and leg $(\mathrm{p}=0.05)$ pain scores (Fig. 4A and B). Coronal placement did not influence VAS back, VAS leg, or ODI scores. There was no significant association between APP and ODI score (Fig. 4C). The patients in group 1 consistently showed the highest performance scores. Compared with them, the patients in group 2 showed the poorest functional results: 12 points higher on average for ODI (not significant), 1.5 points higher for VAS leg pain $(\mathrm{p}=0.05)$, and 1.7 points higher for VAS back pain $(\mathrm{p}=$ $0.04)$. The patients in group 3 had intermediate functional outcome with 5 points higher for ODI, 0.2 points higher for VAS leg pain, and 0.6 points higher for VAS back pain (not significant).

\section{Sagittal Balance Analysis}

On average, $\mathrm{LL}$ was $57^{\circ}\left(95 \%\right.$ CI $\left.53^{\circ}-60^{\circ}\right)$ preoperatively and $62^{\circ}\left(95 \% \mathrm{CI} 58^{\circ}-65^{\circ}\right)$ at D45 $(\mathrm{p}=0.05)$. Average segmental lordosis was $26^{\circ}\left(95 \%\right.$ CI $\left.24^{\circ}-29^{\circ}\right)$ before surgery and $34^{\circ}\left(95 \% \mathrm{CI} 32^{\circ}-36^{\circ}\right)$ at D45 $\left(\mathrm{p}<10^{-5}\right)$. We did not find any significant association between APP and the preoperative or postoperative sagittal balance parameters. Eight of $38(21 \%)$ patients have modified their lumbar sagittal balance after surgery. Among them, 6 (15.8\%) had a normal preoperative lordosis and hyperlordosis after surgery, and $2(5.3 \%)$ were in hypolordosis preoperatively and had an adequate lordosis postoperatively. Compared with the patients who did not modify their balance, the patients who did modify their balance had a lower VAS leg pain score throughout follow-up $(\mathrm{p}=0.02)$. The $21 \mathrm{pa}-$ tients $(55.3 \%)$ with adequate lordosis preoperatively had the best functional outcome throughout their follow-up (Fig. 5). Compared with them, the 5 patients (13\%) with preoperative hypolordosis had the worst functional outcome throughout their follow-up: 2 points higher for VAS leg $(p<0.0001), 1.3$ points higher for VAS back $(p=0.02)$, and 5 points higher for ODI $(\mathrm{p}=0.1)$. The 9 patients $(24 \%)$ with preoperative hyperlordosis had more pejorative initial functional scores: 1.9 points higher for VAS back ( $\mathrm{p}$ $=0.006), 2.4$ points higher for VAS leg $(\mathrm{p}=0.01)$, and 7 points higher for ODI $(p=0.2)$. They retained their hyperlordosis postoperatively, but their functional scores improved postoperatively up to late follow-up, the same as patients with normal lordosis.

\section{Discussion}

The prostheses positioned in front of the center of the L5 endplate provided the smallest gain in local lordosis, without significant variation in global lordosis. The functional outcome was the best in this subgroup. Preoperative sagittal imbalance and changes in sagittal balance postoperatively were associated with the poorest functional outcome.

The clinical impacts of implant positioning are not clear. Measurement of TDR placement differs according to different authors, and some of these methods present serious limitations. Boss et al. ${ }^{1}$ and Le Huec et al. ${ }^{16}$ determined implant placement in millimeters from the posterior aspect of the prosthesis to the posterior aspect of the vertebral body. Neither group found any association between implant position and functional outcome. Kim et al. ${ }^{13}$ used the same method with the ProDisc, but they expressed TDR placement as a percentage related to the length of the vertebral body. They also did not find any correlation between TDR placement and functional outcome. It is not possible to accurately assess the centering of the implant with this technique. Indeed, a small implant may be well centered while its distance to the posterior aspect is great. Likewise, a large implant may be in the anterior part of the vertebra with the same distance to the posterior aspect of the vertebral body. Cinotti, ${ }^{3}$ Patel, ${ }^{21}$ Lemaire,,${ }^{17}$ Jones,,${ }^{10}$ 

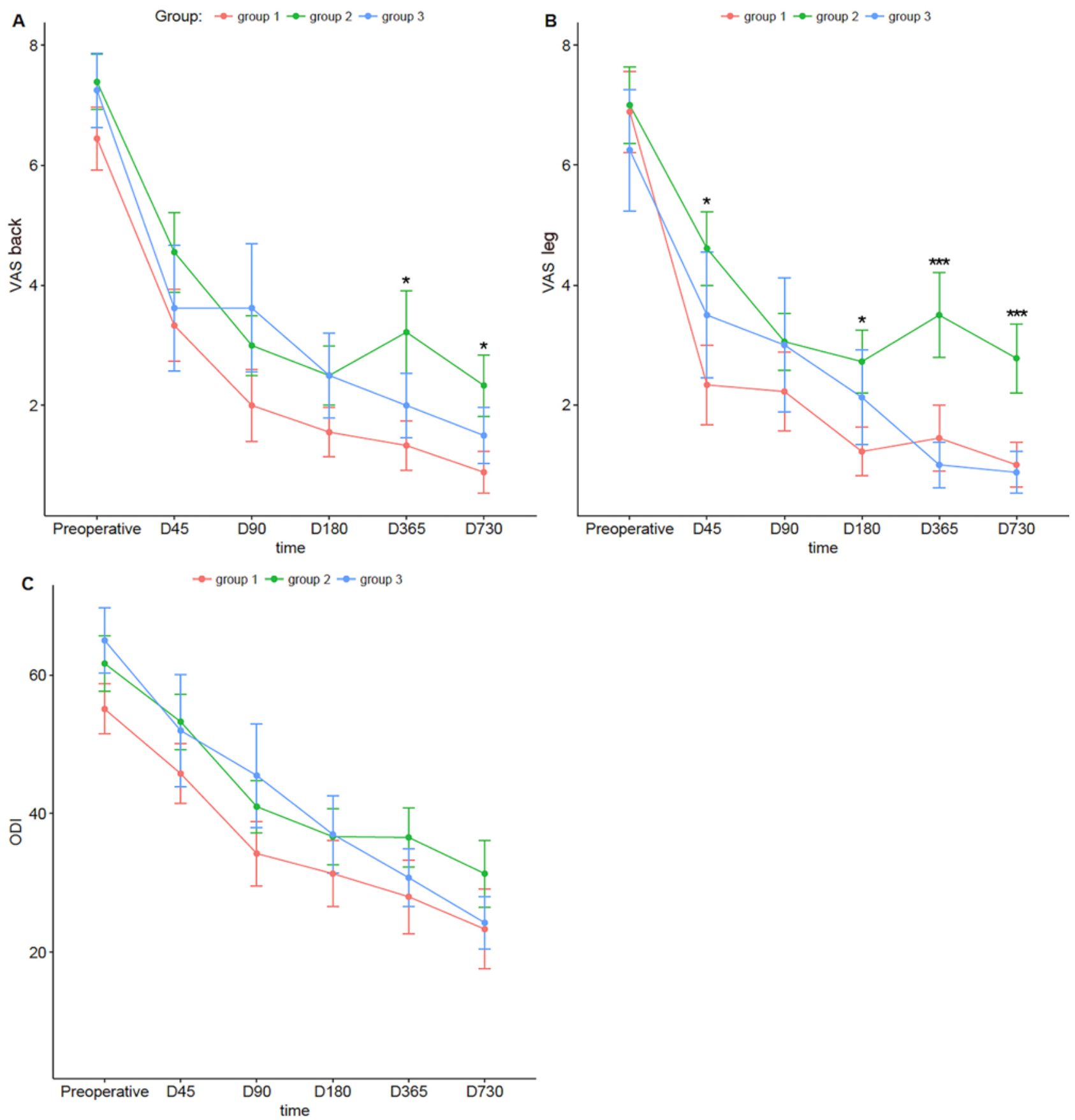

FIG. 4. Better outcomes for an anterior placement. A: VAS back pain progression over time among the 3 groups. There is a significant difference between groups 1 and 2. B: VAS leg pain progression over time among the 3 groups. There is a significant difference between groups 1 and 2. C: ODI progression over time in the 3 groups. ${ }^{*} p<0.05 ;{ }^{* * *} p<0.0001$. Figure is available in color online only.

McAfee, ${ }^{20}$ and Tournier ${ }^{25}$ and their colleagues regarded the vertebral center as a reference. Among these authors, Cinotti et al. ${ }^{3}$ found that the implants placed the most anteriorly had a significantly smaller range of motion than the others. McAfee et al. ${ }^{20}$ and Jones et al..$^{10}$ found worse VAS, ODI, and SF-36 scores among patients with off-centered Charite prostheses, but the authors failed to specify the anterior or posterior nature of the off-centering. We chose to assess the anterior or posterior offset of the implant us- ing both the vertebral and prosthetic centers as references. Our offset measurements were related to the size of the vertebral body to overcome interpatient variability of the size of the vertebral body, as well as scale variations of the radiographs. Moreover, the only variable among the implants was their anteroposterior size and their position, which minimized the confusion bias related to their morphological characteristics.

Functional outcome was better in patients with a pros- 

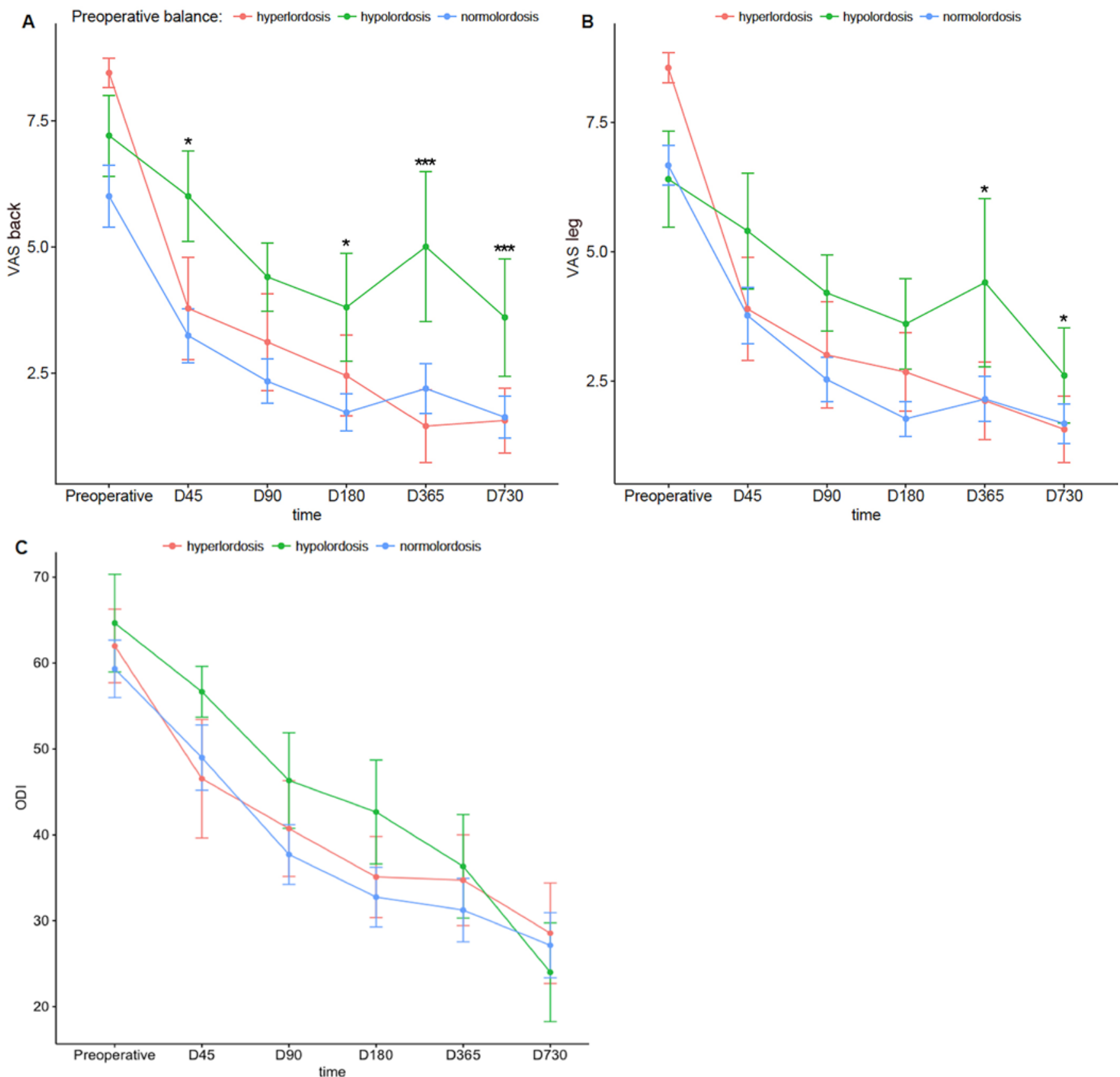

FIG. 5. Better outcomes in cases of normal preoperative LL. A: VAS back pain progression over time according to the preoperative sagittal lumbar balance. There is a significant difference between the normal lordosis and hypolordosis groups. B: VAS leg pain progression over time according to the preoperative sagittal lumbar balance. There is a significant difference between the normal lordosis and hypolordosis groups. C: ODI score progression over time according to the preoperative sagittal lumbar balance. ${ }^{*} p<$ $0.05 ;{ }^{* *} \mathrm{p}<0.0001$. Figure is available in color online only.

thesis placed more anteriorly (group 1). The anterior position corresponds to the stronger part of the vertebral body in terms of compressive strength, and a more anteriorly placed prosthesis leads to the smallest disc resultant force. ${ }^{23}$ It is possible that the most anteriorly placed protheses provided the best compromise between beneficial disc height distraction, ${ }^{2,19,20}$ foraminal size restoration, ${ }^{6}$ and posterior facet joint overstretching. Overstretching could lead to subluxation of facet joints ${ }^{18}$ and an inflammatory response of the ligamentous capsule complex.. ${ }^{9}$ Long-term consequences of anterior positioning on the posterior facet joints remain unknown. Lemaire et al. ${ }^{17}$ described an association between anterior TDR placement and the development of posterior facet osteoarthritis, yet he did not find any influence on functional outcome. The distinction between stretching of the joint capsule and the resultant force on the facet joint seems to be important. Anterior positioning of the prosthesis would cause less stretching of the 
joint capsule and therefore less short-term pain. However, this same positioning could lead to greater constraints and, therefore, in the long term, promote the development of osteoarthritis.

One of the theoretical advantages of a prosthesis in comparison with spinal fusion is the conservation of spinal mobility, enabling the treated segment to dynamically participate in the new sagittal balance. At the segmental level, the increase in segmental lordosis that we observed, followed by a decrease for the prostheses placed most posteriorly, had already been observed in both clinical and biomechanical studies. ${ }^{23,24}$ We think that this loss of segmental lordosis is due to a posterior wedge effect when the prosthesis is too far behind the vertebral center. Improvement in segmental lordosis was not associated with a significant LL increase. The relationship between segmental lordosis and LL is not obvious in the literature. Schmidt, ${ }^{24}$ Lazennec, ${ }^{14}$ Le Huec, ${ }^{15}$ and Faure ${ }^{5}$ and their colleagues did not find any substantial changes in global LL or sacral slope, whereas Katsimihas, ${ }^{12}$ Cakir, ${ }^{2}$ and Tournier ${ }^{25}$ and their colleagues reached the opposite conclusion. We believe that the disc prosthesis is not intended to correct a preexisting sagittal imbalance. Above all, TDR allows the preservation of a preexisting balance. If the preoperative balance is not good, the outcome after TDR seems unfavorable. Patients with normal preoperative lordosis had the best functional results throughout their follow-up in our series, compared with those with hyper- or hypolordosis. There could be several reasons for this, the main one being that preoperative imbalance may be a sign of severity of the initial disc disease and that TDR is not the best option for patients with this condition.

\section{Study Limitations}

This study has several limitations. The first one is a lack of statistical significance due to a lack of power when analyzing the relationship between positional variations of the implants and the sagittal balance profiles. The second limitation is the absence of differences between ODI scores, as some authors, such as Ruiz et al.,22 described this scale as a better indicator of function than the VAS. This can be also linked to a lack of statistical power. Finally, the external validity of our results is restricted since it appears that all variations related to the operated spinal level or implant types may impact the functional outcomes. Our conclusions are probably only valid for patients who undergo surgery at L4 -5 .

\section{Conclusions}

Disc prostheses at L4-5 seem to provide better functional outcome when positioned anteriorly to the center of the vertebral body, probably due to a best compromise between disc height restoration, vertebral body compressive strength, and posterior facet joint stretching. Implant placement influenced segmental lordosis without substantial changes in the global LL. Patients who had preoperative sagittal imbalance or those who significantly modified their balance after the surgery had the poorest outcomes. Particular attention should be paid to preoperative pathological hypolordosis, which appears to be a relevant con- traindication to TDR. A more extensive study with a longer follow-up should be conducted to support these functional results and to analyze the impact of APP on posterior facet joint degeneration.

\section{References}

1. Boss OL, Tomasi SO, Bäurle B, Sgier F, Hausmann ON: Lumbar total disc replacement: correlation of clinical outcome and radiological parameters. Acta Neurochir (Wien) 155:1923-1930, 2013

2. Cakir B, Schmidt R, Huch K, Puhl W, Richter M: [Sagittal alignment and segmental range of motion after total disc replacement of the lumbar spine.] Z Orthop Ihre Grenzgeb 142:159-165, 2004 (German)

3. Cinotti G, David T, Postacchini F: Results of disc prosthesis after a minimum follow-up period of 2 years. Spine (Phila Pa 1976) 21:995-1000, 1996

4. Fairbank JC, Couper J, Davies JB, O'Brien JP: The Oswestry low back pain disability questionnaire. Physiotherapy 66:271-273, 1980

5. Faure A, Khalifé M, Thiebaut B, Roubineau F, Flouzat Lachaniette $\mathrm{CH}$, Dubory A: Influence of the initial sagittal lumbar alignment on clinical and radiological outcomes of single-level lumbar total disc replacements at a minimum 2-year follow-up. Spine (Phila Pa 1976) 43:E959-E967, 2018

6. Gaffey JL, Ghanayem AJ, Voronov ML, Havey RM, Carandang G, Abjornson C, et al: Effect of increasing implant height on lumbar spine kinematics and foraminal size using the ProDisc-L prosthesis. Spine (Phila Pa 1976) 35:17771782,2010

7. Groupe Technique National de Definition des Objectifs: Rapport du GTNDO: Analyse des Connaissances Disponibles sur des Problèmes de Santé Sélectionnés, Leurs Déterminants, et les Stratégies de Santé Publique: Définition d'Objectifs. Paris: La Documentation Française, 2003 (http://www.ladocumentationfrancaise.fr/var/storage/ rapports-publics/034000115.pdf) [Accessed December 31, 2019]

8. Guyer RD, McAfee PC, Hochschuler SH, Blumenthal SL, Fedder IL, Ohnmeiss DD, et al: Prospective randomized study of the Charite artificial disc: data from two investigational centers. Spine J 4 (6 Suppl):252S-259S, 2004

9. Jaumard NV, Welch WC, Winkelstein BA: Spinal facet joint biomechanics and mechanotransduction in normal, injury and degenerative conditions. J Biomech Eng 133:071010, 2011

10. Jones CW, Smitham P, Walsh WR: Relationship of surgical accuracy and clinical outcomes in Charitè lumbar disc replacement. Orthop Surg 4:145-155, 2012

11. Käfer W, Clessienne CB, Däxle M, Kocak T, Reichel H, Cakir B: Posterior component impingement after lumbar total disc replacement: a radiographic analysis of 66 ProDisc-L prostheses in 56 patients. Spine (Phila Pa 1976) 33:24442449, 2008

12. Katsimihas M, Bailey CS, Issa K, Fleming J, Rosas-Arellano P, Bailey SI, et al: Prospective clinical and radiographic results of CHARITÉ III artificial total disc arthroplasty at 2- to 7-year follow-up: a Canadian experience. Can J Surg 53:408-4145, 2010

13. Kim DH, Ryu KS, Kim MK, Park CK: Factors influencing segmental range of motion after lumbar total disc replacement using the ProDisc II prosthesis. J Neurosurg Spine 7:131-138, 2007

14. Lazennec JY, Even J, Skalli W, Rakover JP, Brusson A, Rousseau MA: Clinical outcomes, radiologic kinematics, and effects on sagittal balance of the $6 \mathrm{df}$ LP-ESP lumbar disc prosthesis. Spine J 14:1914-1920, 2014 
15. Le Huec J, Basso Y, Mathews H, Mehbod A, Aunoble S, Friesem T, et al: The effect of single-level, total disc arthroplasty on sagittal balance parameters: a prospective study. Eur Spine J 14:480-486, 2005

16. Le Huec JC, Mathews H, Basso Y, Aunoble S, Hoste D, Bley B, et al: Clinical results of Maverick lumbar total disc replacement: two-year prospective follow-up. Orthop Clin North Am 36:315-322, 2005

17. Lemaire JP, Carrier H, Sariali H, Skalli W, Lavaste F: Clinical and radiological outcomes with the Charité artificial disc: a 10-year minimum follow-up. J Spinal Disord Tech 18:353-359, 2005 (Erratum in J Spinal Disord Tech 19:76, 2006)

18. Liu J, Ebraheim NA, Haman SP, Shafiq Q, Karkare N, Biyani A, et al: Effect of the increase in the height of lumbar disc space on facet joint articulation area in sagittal plane. Spine (Phila Pa 1976) 31:E198-E202, 2006

19. Liu YC, Xia Q, Zhang JD, Xu BS, Hu YC, Ji N, et al: [Effect of intervertebral position on range of motion after artificial lumbar total disc replacement and clinical management.] Zhonghua Yi Xue Za Zhi 90:2750-2754, 2010 (Chinese)

20. McAfee PC, Cunningham B, Holsapple G, Adams K, Blumenthal S, Guyer RD, et al: A prospective, randomized, multicenter Food and Drug Administration investigational device exemption study of lumbar total disc replacement with the CHARITE artificial disc versus lumbar fusion: part II: evaluation of radiographic outcomes and correlation of surgical technique accuracy with clinical outcomes. Spine (Phila Pa 1976) 30:1576-1583, E388-E390, 2005

21. Patel VV, Andrews C, Pradhan BB, Bae HW, Kanim LEA, Kropf MA, et al: Computed tomography assessment of the accuracy of in vivo placement of artificial discs in the lumbar spine including radiographic and clinical consequences. Spine (Phila Pa 1976) 31:948-953, 2006

22. Ruiz FK, Bohl DD, Webb ML, Russo GS, Grauer JN: Oswestry Disability Index is a better indicator of lumbar motion than the Visual Analogue Scale. Spine J 14:1860-1865, 2014

23. Rundell SA, Day JS, Isaza J, Guillory S, Kurtz SM: Lumbar total disc replacement impingement sensitivity to disc height distraction, spinal sagittal orientation, implant position, and implant lordosis. Spine (Phila Pa 1976) 37:E590-E598, 2012
24. Schmidt R, Obertacke U, Nothwang J, Ulrich C, Nowicki J, Reichel $\mathrm{H}$, et al: The impact of implantation technique on frontal and sagittal alignment in total lumbar disc replacement: a comparison of anterior versus oblique implantation. Eur Spine J 19:1534-1539, 2010

25. Tournier C, Aunoble S, Le Huec JC, Lemaire JP, Tropiano $\mathrm{P}$, Lafage V, et al: Total disc arthroplasty: consequences for sagittal balance and lumbar spine movement. Eur Spine J 16:411-421, 2007

26. Tropiano P, Huang RC, Louis CA, Poitout DG, Louis RP: Functional and radiographic outcome of thoracolumbar and lumbar burst fractures managed by closed orthopaedic reduction and casting. Spine (Phila Pa 1976) 28:2459-2465, 2003

27. Zindrick MR, Tzermiadianos MN, Voronov LI, Lorenz M, Hadjipavlou A: An evidence-based medicine approach in determining factors that may affect outcome in lumbar total disc replacement. Spine (Phila Pa 1976) 33:1262-1269, 2008

\section{Disclosures}

Dr. Flouzat Lachaniette: consultant for Groupe Lepine and Biom'Up.

\section{Author Contributions}

Acquisition of data: Boukebous, Meyblum. Critically revising the article: Boukebous. Reviewed submitted version of manuscript: Boukebous, Diviné, Cottin, Flouzat Lachaniette. Study supervision: Bégué.

\section{Correspondence}

Baptiste Boukebous: Beaujon-Bichat Hospital, University of Paris-Nord Val de Seine, Paris, France.baptiste.boukebous@ aphp.fr. 